\title{
Unravelling Hidden Metabolic Capabilities in Microbial Mat Ecosystems by Combining In Situ Measurements and Omic Approaches
}

Mohammad AA Al-Najjar*

Red Sea Research Center, KAUST, Thuwal, Saudi Arabia

\begin{abstract}
Microbial mats are unique ecosystems that harbor diversified metabolic capabilities raging from photosynthesis in the upper layer to fermentation and organic material degradation accompanied with methane production in the deepest layer. Microorganisms in a microbial mat are successful to flourish in extreme environments because they can shift their metabolism in response to the changes in their environment. These metabolic flexibility and capabilities of the microorganisms are underestimated because most of the studies so far have focused on measuring changing in the behavior of the inhabiting microorganisms, or on certain biochemical indicators, or on the shift of microbial community structure. However, to be able to broaden our understanding of the metabolic capabilities, an intensive study of the underlying molecular mechanisms should be carried out. Therefore, the best approach to be adopted is by combining in situ measurements with omics analysis (i.e., matatranscriptomic and/or metaproteomic) in response to changes in the environmental conditions.
\end{abstract}

Microbial mats are complete ecosystems on a millimeter scale that harbor diversified metabolic processes [1-5]. In the upper most layer, photosynthesis is the dominant process because of light, while fermentation and methane production are the most abundant metabolism in the deepest layer [6,7] because of absence of both $\mathrm{O}_{2}$ and light. On the metabolic level, this is indeed comparable to other ecosystems that expand to meters scale such as the marine water column and rainforest [8]. Thriving in extreme habitat (i.e., extreme temperature, high salinity, extreme alkalinity, etc.) is another interesting characteristic that distinguishes microbial mat ecosystem from other complete ecosystems. Apparently, the microorganisms in microbial mat are successful in combating these extreme conditions because they are equipped with unique metabolic capabilities and flexibility. For example, cyanobacteria, which is a ubiquitous biotic component of microbial mats, can switch its metabolism from performing photosynthesis under light availability to aerobic respiration under the absence of light. In addition, cyanobacteria has the ability to perform fermentation under the absence of both oxygen and light $[9,10]$. The metabolic flexibility or persistence of cyanobacteria to suit changes to their dynamic environment explains why they confer fitness advantage. Comparative genomics of different strains of cyanobacteria indicate that they are capable of retaining or shredding genes which improves microbial fitness.

Most of the studies on microbial mats either investigated the behavioral response of their biotic component [11-13], or measured physicochemical indicators such as $\mathrm{O}_{2}, \mathrm{H}_{2} \mathrm{~S}, \mathrm{pH}$, and production of Extracellular Polymeric Substances (EPS) [14,15]. Others investigated the shift in microbial community structure using basic molecular biology techniques or high-throughput sequencing [16,17]. Stronger hypotheses and conclusions are derived from studies that use complimentary approaches to study microbial mats $[18,19]$. However, these studies have missed an important jigsaw to the puzzle as previous research so far is underestimating the metabolic capabilities of each microorganism living in the microbial mats. This knowledge gap can be filled by combining measurements in response to the dynamic changes, together with omics approach (metagenomics, metatranscriptomic, metaproteomic, and metabolomics).

So far, there have been limited studies that adopted this multipronged approach. Subsequently, the results of these studies were very interesting as they have revealed new metabolic possibilities for some of the microorganisms in the microbial mats. Recently, Stuart et al. [20] used a suit of techniques that includes, but not limited to, cell culture, ${ }^{13} \mathrm{C}$-labeling combined with NanoSIMS analysis, EPS separation, detailed biochemical and sugar analysis, and proteomic analysis to conclusively show that cyanobacteria is utilizing the EPS. This interesting finding expands our knowledge about the metabolic flexibility of cyanobacteria and it extends the list of the carbohydrate that they can consume. Such result wouldn't be clear and wellsupported if there was no support from proteomic analysis showing the expression of EPS degrading enzymes that are cyanobacteria-specific enzymes.

Rajeev and his colleagues [21] investigated the biological desert crusts (BDC) and used combined microsensor measurements of photosynthesis and time-series transcriptional analysis after rewetting the dried crust. Their ultimate goal was to understand how cyanobacteria can reactivate its photosynthetic activity. They have shown that cyanobacteria can retain its photosynthetic activity in one hour and this was correlated with raising the anabolic activity of cyanobacteria as shown from their transcriptome. This study provided insight into retaining photosynthesis after rehydrating the BDC, but overlooked the fast resynthesis of chlorophyll (Chl). This important question about rapid $\mathrm{Chl}$ synthesis in response to rehydration has been raised recently from the work of Chennu et al. [13]. In their study, Chennu and his colleagues were able to detect Chl, using combination of HPLC and hyperspectral imaging, in a matter of minutes after rehydrating dried marine microbial mat. In their study, they pointed out that there is a

*Corresponding author: Mohammad Al-Najjar AA, Red Sea Research Center, KAUST Thuwal, Saudi Arabia, Tel: +966 2808 3428; E-mail: Mohammad.alnajjar@kaust.edu.sa

Received December 15, 2015; Accepted December 22, 2015; Published December 29, 2015

Citation: Mohammad Al-Najjar AA (2016) Unravelling Hidden Metabolic Capabilities in Microbial Mat Ecosystems by Combining In Situ Measurements and Omic Approaches. J Microb Biochem Technol 8: 019-020. doi:10.4172/19485948.1000256

Copyright: ㄷ 2016 Mohammad Al-Najjar AA. This is an open-access article distributed under the terms of the Creative Commons Attribution License, which permits unrestricted use, distribution, and reproduction in any medium, provided the original author and source are credited. 
Citation: Mohammad AI-Najjar AA (2016) Unravelling Hidden Metabolic Capabilities in Microbial Mat Ecosystems by Combining In Situ Measurements and Omic Approaches. J Microb Biochem Technol 8: 019-020. doi:10.4172/1948-5948.1000256

need to conduct proteomic analysis to show if cyanobacteria retain the $\mathrm{Chl}$ in an inactive form when the mat is dehydrated or if they are able to retain precursor(s) of Chl synthesis.

All of these interesting studies and research questions that are still open can be best approached by conducting complimentary approaches that show measurements correlated with transcriptomic or proteomic analysis. This combined approach will allow the discovery of novel metabolic capabilities and may help to discover new enzymes that might have very important biotechnological applications.

\section{References}

1. Franks J, Stolz JF (2009) Flat laminated microbial mat communities. EarthScience Reviews 96: 163-172.

2. Bottos EM, Vincent WF, Greer CW, Whyte LG (2008) Prokaryotic diversity of arctic ice shelf microbial mats. Environ Microbiol 10: 950-966.

3. Ferris MJ (2003) Cyanobacterial ecotypes in different optical microenvironments of a 68 degrees $\mathrm{C}$ hot sring mat community revealed by 16S-23S rRNA internal transcribed spacer region variation. Applied and Environmental Microbiology 69: 2893-2898.

4. Foster JS (2009) Molecular and morphological characterization of cyanobacterial diversity in the stromatolites of Highborne Cay, Bahamas. ISME Journal 3: 573-587.

5. Garcia-Pichel F, Lopez-Cortes A, Nubel U (2001) Phylogenetic and morphological diversity of cyanobacteria in soil desert crusts from the Colorado Plateau. Applied and Environmental Microbiology 67: 1902-1910.

6. Des Marais DJ (2003) Biogeochemistry of hypersaline microbial mats illustrates the dynamics of modern microbial ecosystems and the early evolution of the biosphere. Biological Bulletin. 204: 160-167.

7. Al-Thani R (2014) Community Structure and Activity of a Highly Dynamic and Nutrient-Limited Hypersaline Microbial Mat in Um Alhool Sabkha, Qatar. PloS one 9: e92405.

8. Guerrero R, Piqueras M, Berlanga M (2002) Microbial mats and the search for minimal ecosystems. Int Microbiol 5: 177-188.
9. Heyer H, Krumbein WE (1991) Excretion of fermentation products in dark and anaerobically incubated cyanobacteria. Archives of Microbiology 155: 284-287.

10. Stal LJ, Moezelaar R (1997) Fermentation in cyanobacteria. FEMS Microbiology Reviews 21: 179-211.

11. Dillon JG, Miller S, Bebout B, Hullar M, Pinel N, et al. (2009) Spatial and temporal variability in a stratified hypersaline microbial mat community. FEMS Microbiol Ecol 68: 46-58.

12. Pringault O, Garcia-Pichel F (2004) Hydrotaxis of cyanobacteria in desert crusts. Microb Ecol 47: 366-373.

13. Chennu A, Grinham A, Polerecky L, Beer D, Al-Najjar MAA (2016) Rapid reactivation of cyanobacterial photosynthesis and migration upon rehydration of desiccated marine microbial mats. Frontiers in Microbiology 6: 1472.

14. Ludwig R (2005) Photosynthesis-controlled calcification in a hypersaline microbial mat. Limnology and Oceanography 50: 1836-1843.

15. Wieland A, Kühl M (2000) Short-term temperature effects on oxygen and sulfide cycling in a hypersaline cyanobacterial mat (Solar Lake, Egypt). Marine Ecology-Progress Series 196: 87-102.

16. Hollister EB (2010) Shifts in microbial community structure along an ecological gradient of hypersaline soils and sediments. ISME J 4: 829-838.

17. Kunin V (2008) Millimeter-scale genetic gradients and community-leve molecular convergence in a hypersaline microbial mat. Molecular Systems Biology 4: 198.

18. Al-Najjar MAA, Ramette A, Kühl M, Hamza W, Klatt JM (2014) Spatial patterns and links between microbial community composition and function in cyanobacterial mats. Frontiers in Microbiology 5: 406.

19. Jonkers HM, Ludwig R, Wit R, Pringault O, Muyzer G, et al. (2003) Structura and functional analysis of a microbial mat ecosystem from a unique permanent hypersaline inland lake: 'La Salada de Chiprana' (NE Spain). FEMS Microbiol Ecol 44: 175-189.

20. Stuart RK, Mayali X, Lee JZ, Craig Everroad R, Hwang M, et al. (2016) Cyanobacterial reuse of extracellular organic carbon in microbial mats. ISME J.

21. Rajeev L, da Rocha UN, Klitgord N, Luning EG, Fortney J, et al. (2013) Dynamic cyanobacterial response to hydration and dehydration in a desert biological soil crust. ISME J 7: 2178-2191. 